\title{
Plain packaging of cigarettes: do we have sufficient evidence?
}

This article was published in the following Dove Press journal:

Risk Management and Healthcare Policy

2 April 2015

Number of times this article has been viewed

\section{Collin N Smith' \\ John D Kraemer ${ }^{2}$ \\ Andrea C Johnson' \\ Darren Mays'}

'Department of Oncology, Georgetown University Medical Center, Lombardi Comprehensive Cancer Center, Washington, DC, USA; ${ }^{2}$ Department of Health Systems Administration, School of Nursing and Health Studies, Georgetown University, Washington, DC, USA
Correspondence: Darren Mays Department of Oncology, Georgetown University Medical Center, Lombardi Comprehensive Cancer Center, 3300 Whitehaven Street NW, Suite 4100, Washington, DC 20007, USA

Email dmm239@georgetown.edu
Abstract: Tobacco industry marketing is a primary factor influencing cigarette smoking behavior and the cigarette pack has become an important marketing vehicle for tobacco companies. Standardized "plain" cigarette packaging is advocated as a public health policy to prevent and reduce morbidity and mortality caused by smoking by reducing youth smoking initiation and promoting cessation among smokers. Plain packaging was implemented in Australia in December 2012, and several other countries are considering doing so, but each faces foreseeable legal resistance from opponents to such measures. Tobacco companies have challenged these public health policies, citing international trade agreements and intellectual property laws. Decision-making in these court cases will hinge in part on whether the evidence indicates the public health benefits of plain packaging outweigh any potential harm to tobacco manufacturers' interests. We reviewed the available evidence in support of plain packaging, finding evidence from observational, experimental, and population-based studies. Results indicate that plain packaging can reduce positive perceptions of smoking and dissuade tobacco use. Governments deciding to implement plain cigarette packaging measures can rely on this evidence to help make a strong case that plain packaging plays an important role in the context of comprehensive smoking prevention efforts.

Keywords: cigarette smoking, tobacco, plain packaging, regulation, policy

\section{Introduction}

Cigarette smoking is the leading preventable cause of death globally. The World Health Organization (WHO) estimates there are over 1 billion smokers worldwide. Despite reductions in the prevalence of smoking in developed countries, smoking is increasing globally. ${ }^{1}$ Tobacco, including cigarette smoking, kills 5.4 million people a year and is a risk factor for six of the eight leading causes of deaths in the world. ${ }^{1}$ Recent evidence also indicates that smoking contributes to more morbidity than was evident previously. ${ }^{2,3}$ Smoking also incurs significant financial costs to society. An estimated US $\$ 500$ billion are lost each year due to health care expenditures, lost productivity, and other financial costs due to smoking. ${ }^{3}$ In light of the significant public health and financial impact incurred by smoking, preventing smoking initiation and promoting cessation are global public health goals. ${ }^{4}$

Although many factors influence tobacco use behavior, tobacco industry marketing and promotions stand out as a prominent factor encouraging tobacco use. ${ }^{5}$ Tobacco companies spend tens of billions of dollars each year to promote their products, ${ }^{6}$ and exposure to tobacco industry promotions has been causally linked to youth tobacco use. ${ }^{5,7}$ Due to increasing restrictions on tobacco advertising and marketing, cigarette 
packaging has become a crucial promotional medium. ${ }^{5}$ Evidence demonstrates that cigarette packaging, including the pack format (size, shape, opening), colors, logos, and descriptors impact consumer perceptions of the health risks of smoking, perceived appeal of tobacco products, and attitudes toward smoking. ${ }^{8-18}$ As others have noted, the cigarette pack is a valuable marketing tool to the tobacco industry because it represents a direct link between tobacco manufacturers and consumers, and smokers and non-smokers are exposed to cigarette packs because they are visible with each product use. ${ }^{19,20}$ Some have described cigarette packs as a "silent salesmen" for tobacco companies. ${ }^{21}$

Consequently, cigarette package regulations are advocated as part of a comprehensive set of policies to reduce tobacco use and associated morbidity and mortality. Article 11 of the WHO's Framework Convention for Tobacco Control (FCTC), an international health treaty to reduce the global public health toll of tobacco use, recommends graphic warning labels for cigarette packages conveying the health risks of smoking using text and imagery. ${ }^{22}$ FCTC guidelines recommend graphic warning labels cover $\geq 30 \%$ of the front and back of the pack surface, and advocate upward of $50 \%$ to optimize their impact. ${ }^{23}$ Globally, more than 60 countries have adopted or are considering adopting graphic warning labels for cigarette packs as a public health policy measure. ${ }^{24}$ Empirical evidence indicates strong, graphic warnings have an impact in reducing tobacco use. ${ }^{14,25-33}$ Article 11 of the FCTC also recommends regulations prohibiting the use of false or misleading descriptors, such as low, light, and mild, and more than 50 countries have enacted such prohibitions. $^{20}$

Standardized, plain cigarette packaging ("plain packaging") is another potential public health policy for reducing tobacco use. Plain packaging regulations strip cigarette packs of all branding elements, including colors and logos, and mandates that all cigarette packaging be a standardized color (eg, brown) and display only a brand name in a required font style and format. ${ }^{20,34,35}$ Article 11 of the WHO FCTC states that signatories "should consider adopting measures to restrict or prohibit the use of logos, colors, brand images or promotional information on packaging other than brand names and product names displayed in a standard color and font style (plain packaging)". ${ }^{22}$ Plain packaging was first raised as a public health policy strategy in the late 1980s by the New Zealand government. ${ }^{19}$ In the early 1990 s, plain packaging was considered by the Canadian government, but ultimately was not enacted. ${ }^{19}$ Now, plain packaging is considered as part of a comprehensive public health strategy striving to eliminate the morbidity and mortality caused by tobacco use, ${ }^{36}$ primarily by reducing youth cigarette smoking initiation as well as promoting cessation among current smokers. ${ }^{34,37}$ In 2012, Australia became the first country to introduce plain packaging through the Tobacco Plain Packaging Act. ${ }^{38}$ The law was enacted despite legal resistance and public relations campaigns against the measure by the tobacco industry, ${ }^{21}$ ultimately being upheld by the High Court of Australia. ${ }^{39}$ Cigarette packages in Australia are now required to use standardized brown-colored packaging and to display graphic warning labels covering $75 \%$ of the front and $90 \%$ of the back of all packs. Several other countries are considering similar plain packaging policies, including France, Scotland, the UK, and New Zealand.

Proponents of plain packaging argue it can prevent youth smoking initiation and promote cessation among current smokers by reducing the appeal of cigarettes, increasing attention to health warning labels, and affecting smokingrelated attitudes and beliefs..$^{20,22,34,37,40,41}$ Opponents of plain packaging, including tobacco manufacturers, retailers, and some governments, argue that such policies are economically harmful (eg, revenue and job loss), increase illicit trade of contraband tobacco products, and lack scientific support to demonstrate that they can reduce tobacco use. ${ }^{19,42}$ Ultimately, any government considering implementing a plain packaging policy will likely face legal challenges similar to Australia's experience. Tobacco manufacturers and their representatives have also challenged such policies on the grounds that they violate international trade and trademark laws. ${ }^{19,21,43}$ One major international tobacco company has preemptively indicated they will do so in the UK where plain packaging legislation has not yet been introduced but is under consideration. ${ }^{44}$ Challenges under national constitutions or other domestic law would likely arise in some countries as well.

The outcome of these legal challenges will be based on interpretation of applicable laws and international trade agreements in a given country's courts. ${ }^{42}$ However, as has recently been the case with implementing similar cigarette packaging regulations, the available scientific evidence will play a crucial role in decisions surrounding plain packaging policies. ${ }^{45,46}$ Others have previously reviewed the evidence on plain packaging for cigarettes. ${ }^{19,20,47}$ The goal of this review was not to duplicate prior work, but to examine the existing evidence in the current policy climate to understand the potential viability and impact of plain packaging as a public health measure to reduce the burden of tobacco use. We organized the review around the evidence that plain packaging could prevent youth tobacco use and 
reduce smoking among adults, given these two populations are critical to reduce the global burden of cigarette smoking. A well-established framework for evaluating public health policies for reducing tobacco use guided this analysis. ${ }^{48}$

\section{Preventing youth cigarette smoking}

It is estimated that $90 \%$ of all adults who smoke cigarettes begin smoking before 18 years of age. ${ }^{3}$ This makes preventing youth cigarette smoking a primary means to reduce tobacco use. ${ }^{23}$ Studies have examined the potential impact of plain packaging for achieving this goal using a variety of methods, focusing on how plain packaging may affect youth's perceptions of cigarettes, perceptions of smoking, and other cognitive and attitudinal factors that influence youth tobacco use.

Qualitative studies have investigated youth's perceptions of plain cigarette packaging using methods such as focus groups. McCool et $\mathrm{al}^{49}$ conducted 12 focus groups with 80 New Zealand youths ages $14-16$. Youths perceived that regulations involving both plain packaging and strong, graphic health warnings would be the most effective approach to reduce the appeal of smoking among youths and increase perceptions that smoking is harmful. ${ }^{49}$ Scheffels and Saebo ${ }^{50}$ also conducted five focus groups among Norwegian youths ages 16-21, including non-smokers, occasional smokers, and daily smokers. Compared with fully branded cigarette packs, plain packages were perceived less favorably and were thought to no longer convey the positive brand imagery that is typically communicated through cigarette packs. Finally, Van Hal et $\mathrm{al}^{51}$ also conducted eight focus groups with a total of 55 Flemish adolescents ages 15-18, including current smokers and prior experimenters. Youths perceived plain packs as less attractive than branded packs, and believed plain packs are more likely to draw attention to health warning labels displayed on the packs.

Others have investigated youth's perceptions of plain cigarette packaging by exposing them to images or examples of plain cigarette packs in cross-sectional behavioral surveys. Ford et $\mathrm{al}^{52}$ surveyed 1,025 youths ages 11-16 from the UK as part of the UK Youth Tobacco Policy survey. They examined adolescents' perceptions of plain cigarette packs relative to regular branded packs and branded packs with novel features (eg, unique shape, opening). Although youths viewed all types of packs negatively overall, plain packs were viewed less favorably than any of the branded packs. Moodie et $\mathrm{al}^{53}$ conducted a similar online survey with $658 \mathrm{UK}$ youths ages 10-17. Youths perceived that plain cigarette packs were unattractive (91\%), uncool (87\%), and were packs that young people would not want to be seen with $(88 \%) .{ }^{53}$ Youths also indicated that smokers of cigarettes from plain packs were unpopular (59\%), boring (63\%), unfashionable (67\%), and older people $(69 \%) .{ }^{53}$ Youths who had never tried smoking were more likely than those who had tried smoking to hold such negative beliefs.

Several studies have also used experimental methods to examine youth's perceptions of plain cigarette packs. Germain et $\mathrm{l}^{54}$ conducted an experiment with 1,087 Australian youths ages 14-17 to examine the effects of plain packaging and graphic health warnings on cigarette packs. Plain packaging reduced youth's positive perceptions of cigarette packs, led to more negative perceptions of smokers, and reduced perceived quality of the cigarettes within the packs. These effects were similar among non-smokers who were susceptible to smoking in the future, those who had previously tried smoking, and youths who were current smokers. Larger graphic warning labels produced further reductions in youth's perceptions of cigarette packs.

Hammond et al conducted experimental studies examining the impact of plain packaging on youth's perceptions of cigarette packs and other outcomes related to smoking behavior. ${ }^{20,55,56}$ In one study with 806 UK youths ages 11-17, plain packs were rated as less attractive, reduced false beliefs about the health risks and addictiveness of smoking, and were less appealing to youth to try relative to branded packs. ${ }^{20}$ In another experimental study with 947 female UK youths ages 11-17, participants were randomly assigned to view branded or plain cigarette packs. Compared with all branded packs, plain packs were rated least appealing and worse tasting, were associated with fewer false beliefs about the health risks of smoking, and were related to less-positive perceptions of smokers using those packs. ${ }^{55}$ Female youths were also significantly less likely to indicate they would accept a pack of cigarettes when offered a plain pack versus a branded pack. ${ }^{55}$ In another experimental study of 712 UK youths ages 11-17, participants viewed pairs of cigarette packs that displayed one of three health warning labels (40\% text, $40 \%$ graphic, or $80 \%$ graphic) on one of two plain pack colors (white versus brown). ${ }^{56}$ Compared with the branded packs, the plain packs were perceived as less attractive and were less likely to encourage smoking initiation. The larger health warnings were more likely to be reported as impactful. ${ }^{56}$

Two studies reported on results of an experiment conducted with 1,022 Norwegian youths ages $15-22 .{ }^{57,58}$ Participants were randomized to view regular branded cigarette packs, plain cigarette packs without descriptors, and plain packs with descriptors. Plain packaging reduced 
positive perceptions of smokers, and these results held for females in multivariable analyses adjusting for potential confounders. Finally, Maynard et al ${ }^{59}$ conducted an experiment with 87 UK adolescents ages 14-19 using eye-tracking to determine whether plain packaging affects youth's visual attention to graphic warning labels compared with branded packs. There were more eye movements to health warnings on plain packs versus branded packs, whereas on branded packs, youths devoted equal time viewing the warning labels and pack branding. This pattern of findings was evident among experimenters and weekly smokers, but not among never smokers or daily smokers.

\section{Reducing adult cigarette smoking}

Among smokers, quitting smoking at any time significantly reduces the lifetime risk of tobacco-associated morbidity and mortality. ${ }^{60}$ Indeed, policies designed to help smokers quit are essential to reduce the global burden of tobacco use. ${ }^{22}$ Like the studies conducted among youths, research has examined the potential impact of plain packaging measures for reducing adult cigarette smoking using various methodological approaches.

Some investigations of plain packaging among adults have used qualitative methodologies. Arora et al ${ }^{61}$ used a mixed-methods study involving focus groups, interviews with public officials, and public opinion survey data collection to assess perceptions and support for potential plain packaging regulations in India. Plain packaging was favored by most participants and key stakeholders. Perceptions indicated "packaging attracts people" and that plain packaging would reduce the appeal of cigarette packs and diminish the role of packs as a promotional tool. Participants also indicated plain packaging would motivate smokers to quit. Hoek et al ${ }^{62}$ conducted focus groups examining identity perceptions of plain packaging among 86 young adult smokers and nonsmokers. Results indicated that plain packaging would reduce the appeal of cigarettes and diminish the role of cigarette branding in shaping young adults' social connotations of smoking. Furthermore, Scheffels and Saebo ${ }^{50}$ conducted six focus groups among Norwegian young adults, including daily and former smokers. Thematic results outlined that plain packages were perceived less favorably than branded packs, and were thought to reduce the brand appeal of cigarettes.

Researchers have also used cross-sectional surveys to assess perceptions of plain packaging and other relevant outcomes. Borland and Savvas ${ }^{63}$ surveyed Australian young adults ages 18-29 to investigate the impact of cigarette red, blue, gold, silver, and white packaging coloring and presence of flavor descriptors (eg, ultimate, smooth) and other packaging attributes on perceived quality, taste, harms, and level of tar of the cigarettes in each pack. Perceptions varied by all types of descriptors examined, demonstrating that even on plain packaging without any other branding elements, pack coloring and descriptors can influence perceptions. Gallopel-Morvan et al ${ }^{64}$ surveyed nearly 900 adult smokers and non-smokers in France to assess their perceptions of regular branded packs, packs with novel features (eg, pack shape, opening), and plain packs. Plain packs were perceived to be less attractive, less attention grabbing, and less likely to be purchased by youths compared with branded and novel packs. Plain packs were also perceived as the most effective for motivating smokers to quit. Hoek et $\mathrm{al}^{65}$ surveyed more than 800 smokers and non-smokers in New Zealand to assess their support of plain packaging regulations and perceived effectiveness of plain packaging. Nearly $70 \%$ supported plain packaging, and support was more likely among nonsmokers versus smokers and among women than among men. Non-smokers were more likely than smokers to perceive that plain packs would motivate smokers to quit.

Other investigators have used "naturalistic" methods aiming to approximate the real-world experience of using plain cigarette packages. ${ }^{66-68}$ Gallopel-Morvan et al ${ }^{66}$ examined the impact of plain packaging among 133 French roll-yourown cigarette smokers ages 18-25. Participants used plain roll-your-own packs provided by researchers for 10 days. They completed baseline and follow-up surveys of their perceptions of the packs, the product, the brands, and other outcomes. Compared to their usual "fully" branded packs, plain packs were associated with less positive pack and product perceptions, lower brand attachment, and less positive feelings about smoking. Participants were also more likely to report being motivated to quit when using the plain packs.

Moodie et al conducted two similar studies. ${ }^{67}$ In one study, 48 smokers used their regular branded packs for 2 weeks and used plain packs provided by the researchers for 2 weeks. During each period, participants completed surveys assessing outcomes. ${ }^{67}$ Compared with branded packaging, plain packaging increased negative attitudes about the pack and smoking, increased avoidant behavior (hiding the pack, covering the pack); increased smoking cessation behaviors (smoking less when around others, foregoing cigarettes); and increased thoughts about quitting. Moodie et al conducted another study where 187 young adult women ages 18-35 used plain cigarette packs that were provided by the researchers for 1 week, used their own branded packs for 1 week, and completed outcome assessments during each period. ${ }^{68}$ 
Compared to branded packaging, plain packaging led to more negative perceptions and feelings about the pack and smoking, and increased tobacco avoidant behaviors.

Several studies have examined plain packaging among adults using experimental methods. These studies have included adults from several countries including Australia, ${ }^{69-71}$ Canada, ${ }^{72}$ the US, ${ }^{73,74}$ UK,,${ }^{20,75-77}$ and Brazil. ${ }^{78}$ Typically, participants were randomized to view plain cigarette packs or regular branded packs, and differences in perceptions of packaging and other smoking-related outcomes were assessed. The results consistently showed that adults perceived plain cigarette packs to be less attractive and less appealing than branded packs, perceived the quality of the cigarettes (eg, taste, smoothness) contained in plain packs to be lower, and that plain packaging reduced false beliefs about the potential harms and addictiveness of smoking. ${ }^{13,69-71,78}$ Plain packaging was also shown to reduce the likelihood that smokers would purchase cigarettes, ${ }^{69}$ reduce purchase demand for cigarettes, ${ }^{74}$ and reduce tobaccoseeking behavior. ${ }^{75}$

Some experiments examined the potential interactions between graphic health warning labels and plain packaging. ${ }^{70,73,74}$ In general, these studies showed that the combination of plain packaging and graphic warning labels significantly affects adults' perceptions of cigarettes and other related outcomes. ${ }^{73,74}$ However, there is evidence that plain packaging affects these outcomes independent of graphic warning labels. ${ }^{70}$

Finally, two studies used eye-tracking to experimentally examine whether plain packaging affects adults' visual attention to the warning labels on cigarette packs. In a sample of 30 nicotine dependent adult smokers, Maynard et $\mathrm{al}^{76}$ found that although smokers predominantly fixated on the branding rather than the health warning, time spent viewing the branding relative to the health warnings was smaller for plain packs. For branded packs, smokers' attention was on the branding for the entire time that packs were viewed. Munafò et $\mathrm{al}^{77}$ also assessed the impact of plain packaging on visual attention toward cigarette pack health warnings using eye-tracking among non-smokers, weekly smokers, and daily smokers. Non-smokers and weekly smokers, but not daily smokers, devoted greater visual attention to the health warnings on plain packs versus branded packs.

\section{Population data from Australia's experience}

Surveillance data gathered in Australia provide populationlevel information on the impact of plain packaging once it has been implemented in a real-world setting. Wakefield et $\mathrm{al}^{79}$ analyzed cross-sectional survey data collected in Victoria, Australia during the initial roll-out phase of plain packaging regulations. Compared with branded pack smokers, those smoking from plain packs perceived their cigarettes to be lower in quality and less satisfying, were more likely to think about quitting in the past week, and were more likely to indicate that quitting was important. Over time as the roll-out continued and more branded pack smokers transitioned to plain packs, their perceptions changed to be similar to those who were among the first to be using plain packs.

From 2006 to 2013, before and shortly after implementation of plain packaging, Dunlop et $\mathrm{al}^{80}$ examined data from serial, cross-sectional surveys conducted with $>15,000$ Australians. After the plain packaging regulations took effect, there was a significant increase in the number of smokers reporting strong cognitive and emotional responses to graphic warning labels, suggesting plain packaging increased the warning's effects on cognitions and emotions related to quitting smoking. There were also increases in the number of smokers who perceived cigarette packs to be unattractive and indications of negative brand appeal. These changes persisted 3 months and 6 months after implementation. Young et $\mathrm{al}^{81}$ investigated trends in calls to a telephone quit line after implementing plain packaging in Australia. They found a relative $78 \%$ increase in the number of smokers calling the quit line per week following the implementation of plain packaging, after adjusting for seasonal trends and several other potential confounding variables.

Swift et $a^{82}$ used survey data to examine Australian smokers' attitudes toward plain packing before and after implementation, predictors of attitude change, and the relationship between support of plain packaging and quitting smoking. Support for plain packaging increased after implementation, support of the law was associated with greater perceived risks of smoking, stronger motivation to quit, and lower addiction.

Zacher et $\mathrm{al}^{83}$ examined whether cigarette pack display and smoking at outdoor venues changed after Australia's plain packaging law was introduced. Before and after implementation, the researchers enumerated patrons, smokers, and tobacco packs at cafés, restaurants, and bars with outdoor seating. Visible pack display declined by $15 \%$ and active smoking dropped $23 \%$. The decline in pack display was stronger in venues with children present, and was limited to mid and high socioeconomic status areas. The proportion of packs concealed (eg, by cell phones, wallets) increased, 
though this practice was limited to a small proportion of smokers observed $(<10 \%)$.

Additionally, the Australian Government Department of Health recently reported population data on tobacco control outcomes after plain packaging was implemented. Australia experienced its lowest recorded level of cigarette consumption in the first quarter of 2014, cigarette sales fell by 3\% from 2012 to 2013, and the number of daily smokers ages 14 and older decreased from $15.1 \%$ in 2010 to $12.8 \%$ in $2013 .{ }^{84}$ Although these changes cannot be directly attributable to plain packaging alone, they are strongly suggestive that plain packaging is contributing to decreases in smoking at the population level.

\section{Studies examining the potential detrimental impact of plain packaging}

Plain packaging opponents argue that such policies are economically harmful (eg, revenue and job loss) and increase illicit trade. ${ }^{19,42}$ Several studies examined these claims, including studies using data from Australia's recent experience. Carter et $\mathrm{a}^{85}$ experimentally examined whether plain packaging increases retail transaction times, which could lead to diminished revenue for retailers. Average transaction time was significantly faster for plain compared with branded packs, and $40 \%$ of participants made one or more mistakes when selecting from branded packs versus $17.3 \%$ with plain packs. Carter et $\mathrm{al}^{86}$ also conducted an observational study to examine the impact of plain packaging on retail transaction times before and immediately after implementation. The researchers timed retail transactions at 100 tobacco retailers after requesting one of 17 popular cigarette brands (randomly selected). After plain packaging implementation, retailer selection times and errors decreased, and average transaction time declined. Bayly et a ${ }^{87}$ and Wakefield et a ${ }^{88}$ conducted similar observational studies of tobacco retailers in Australia and the findings were similar, with no increases in pack retrieval transaction times after plain packaging implementation.

Plain packaging opponents argue that it will increase counterfeit tobacco purchasing. Moodie et a $1^{89}$ conducted focus groups with 54 adult smokers, finding that smokers believed plain packaging would have little impact on their ability to identify counterfeit tobacco or on counterfeit tobacco purchases. Scollo et al ${ }^{90}$ investigated whether smokers were more likely to purchase illicit tobacco, using data from serial cross-sectional surveys conducted before and after plain packaging was implemented in Australia. They found no evidence that illicit tobacco purchases changed. Scollo et a ${ }^{11}$ investigated the availability of illicit tobacco in small retail outlets in Australia after the implementation of plain packaging in a field observational study. Similarly, no changes in illicit tobacco availability were found.

\section{Implications for plain packaging implementation}

Studies deploying a range of methodologies, including observational and experimental research, consistently show that plain packaging can reduce the appeal of cigarettes, decrease the power of the cigarette pack as a marketing vehicle, increase attention to the health warning labels, and impact smoking-related attitudes and cognitions. Evidence from Australia comparing population-level data gathered before and after plain packaging was implemented in late 2012 shows similar findings. Studies of the potential adverse effects of plain packaging have shown that plain packaging does not increase retail transaction times, and there is no observable increase in use of illicit or counterfeit tobacco. Nonetheless, opponents of plain packaging have presented significant challenges to the widespread adoption of plain packaging. Following the proposal of the Tobacco Plain Packaging Act in Australia, one major transnational tobacco company transferred ownership of its Australian operation to Hong Kong in order to file a dispute of the proposed law under a bilateral investment treaty between Hong King and Australia. ${ }^{43}$ In an ongoing case, the company argues that their interests in Australia are protected by a clause in the treaty ensuring fair and equitable treatment provisions. As noted above, the same company has also indicated they would launch legal opposition to a plain packaging measure that has been under consideration in the UK. ${ }^{44}$ However, others observed that transnational tobacco companies have relied on unsubstantiated evidence mired with undisclosed conflicts of interest to argue against plain packaging, ${ }^{92}$ and that opposition to cigarette packaging regulations under the auspices of international trade law is based on tenuous legal arguments, at best. ${ }^{37,43} \mathrm{~A}$ recent analysis of internal tobacco industry documents suggests their own legal counsel advised that international trade agreements do not provide adequate legal grounds to preclude packaging regulation. ${ }^{43}$

The use of bilateral investment treaties is a common strategy used by the tobacco industry to thwart regulation, and one that will likely be used against plain packaging requirements. In addition to the Australian case currently underway, a major tobacco company has challenged Uruguay's pack content restrictions and graphic warning label requirements 
via a bilateral investment treaty with Switzerland. Among other claims, the company argued that Uruguay's requirements expropriated and deprived the company of its property interests. There is variation in treaty language, but expropriation occurs when a government interferes with property rights, and it generally requires additional factors, such as a lack of a bona fide public purpose, trade discrimination, or harm to the property interest that is disproportionate to the public benefits. ${ }^{93}$ This suggests that tobacco regulators will succeed in defending plain packaging and other package regulation, to the extent that they can demonstrate through scientific evidence that regulation engenders significant public health benefits that outweigh their interference with property interests.

Lobbying organizations representing the interests of international tobacco companies, including the American Legislative Exchange Council, have also indirectly challenged the legitimacy of the Australian plain packaging law under current World Trade Organization (WTO) intellectual property agreements. ${ }^{94}$ Since private companies cannot lodge complaints to the WTO, the American Legislative Exchange Council has provided funds and council to several countries, including Honduras, Cuba, the Dominican Republic, and Ukraine to contest the legality of the Tobacco Plain Packaging Act in Australia. ${ }^{95}$ These challenges, which allege improper technical barriers to trade and interference with intellectual property rights, are currently being reviewed through the WTO dispute process. Whether plain packaging constitutes what WTO law calls an "encumbrance" on intellectual property rights depends on if public health gains justify the deprivation of property interests and whether a less restrictive alternative exists. In general, compared to other package restrictions, plain packaging requirements should be able to endure the intellectual property claims. ${ }^{96}$ However, as a recent trade dispute between the US and Indonesia has shown, it is important that countries require plain packaging for all similar tobacco products, lest they risk being found to have employed a discriminatory technical barrier to trade in violation of WTO law. ${ }^{97}$ For example, a country that predominantly imports cigarettes but produces smokeless tobacco domestically cannot require plain packaging of cigarettes only.

Legal systems in individual countries are obviously unique, and the acceptability of plain packaging will vary accordingly. For example, the legality of plain packaging was upheld by the Australian High Court. ${ }^{39}$ However, legal disputes over graphic warning labels required by the Family Smoking Prevention and Tobacco Control Act in the US and delayed implementation of plain packaging measures in the
UK suggest that tobacco companies will often file domestic litigation as well. Plain packaging - like any restriction on commercial expression - is particularly complicated in settings where the tobacco industry alleges constitutional free expression violations. To prevail, the governments would need to demonstrate that plain packaging directly advances the important public interest of promoting the nation's health. ${ }^{98}$ As with most legal challenges to public health regulation, the integral question is the extent to which strong scientific evidence makes it likely that the benefits of regulation outweigh the harm to corporate interests - though the extent to which the balance must tilt in favor of strong evidence of public health benefit differs from country to country. While countries considering plain packaging measures should expect resistance, the evidence reviewed herein suggests that such measures can substantially improve public health. Ultimately, plain packaging cases will be decided on a country-by-country basis, while still operating under relevant intellectual property, bilateral investment, and trade agreements.

It is important to be mindful that plain packaging represents one potential policy measure that can be deployed as part of a suite of comprehensive public health strategies to reduce morbidity and mortality caused by tobacco use. ${ }^{42}$ For example, in several studies reviewed, plain packaging was examined along with graphic health warning labels, and in Australia larger warnings were required at the same time that plain packaging was implemented. Despite this overlap, strong, graphic warnings existed in Australia prior to plain packaging implementation, suggesting the changes in tobacco-related outcomes are attributable at least in part to implementing plain packaging. Further evidence, such as the studies by McCool et al and Scheffels and Saebo ${ }^{49,50}$ indicates that plain packaging accompanied by strong, graphic warnings can influence public health outcomes, such as promoting smoking cessation. However, the impact of measures such as plain packaging for increasing smoking cessation will likely be limited if not accompanied by other components of a comprehensive approach to tobacco control, consistent with FCTC recommendations. ${ }^{22}$ In conclusion, our review indicates there is sufficient empirical evidence to support implementing plain packaging as part of a comprehensive suite of public health measures designed to reduce morbidity, mortality, and financial costs caused by tobacco use.

\section{Acknowledgments}

Preparation of this publication was supported in part by the National Cancer Institute (NCI) and US Food and Drug 
Administration (FDA) Center for Tobacco Products (CTP) under National Institutes of Health (NIH) Award Number K07CA172217 (PI: D Mays). The content is solely the responsibility of the authors and does not necessarily represent the official views of the NIH or the FDA.

\section{Disclosure}

The authors have no conflicts of interest to disclose.

\section{References}

1. World Health Organization [homepage on the Internet]. Tobacco Free Initiative (TFI). Tobacco facts. Available from: http://www.who.int/ tobacco/mpower/tobacco_facts/en/. Accessed January 28, 2015.

2. Rostron BL, Chang CM, Pechacek TF. Estimation of cigarette smoking-attributable morbidity in the United States. JAMA Intern Med. 2014;174(12):1922-1928.

3. US Department of Health and Human Services. The Health Consequences of Smoking: 50 Years of Progress. A Report of the Surgeon General. Atlanta, GA: US Department of Health and Human Services, Centers for Disease Control and Prevention, National Center for Chronic Disease Prevention and Health Promotion, Office on Smoking and Health; 2014.

4. World Health Organization [homepage on the Internet]. Media centre fact sheets. Noncommunicable diseases. [Updated Jan 2015]. Available from: http://www.who.int/mediacentre/factsheets/fs355/en/. Accessed January 28, 2015.

5. Henriksen L. Comprehensive tobacco marketing restrictions: promotion, packaging, price and place. Tob Control. 2012;21(2):147-153.

6. World Health Organization [homepage on the Internet]. Tobacco Free Initiative (TFI). WHO report on the global tobacco epidemic 2013. Available from: http://www.who.int/tobacco/global_report/2013/en/. Accessed January 28, 2015.

7. Lovato C, Watts A, Stead LF. Impact of tobacco advertising and promotion on increasing adolescent smoking behaviours. Cochrane Database Syst Rev. 2011;(10):CD003439.

8. Bansal-Travers M, Hammond D, Smith P, Cummings KM. The impact of cigarette pack design, descriptors, and warning labels on risk perception in the US. Am J Prev Med. 2011;40(6):674-682.

9. Borland R, Savvas S, Sharkie F, Moore K. The impact of structural packaging design on young adult smokers' perceptions of tobacco products. Tob Control. 2013;22(2):97-102.

10. Brown A, McNeill A, Mons U, Guignard R. Do smokers in Europe think all cigarettes are equally harmful? Eur J Public Health. 2012; 22 Suppl 1:35-40.

11. Doxey J, Hammond D. Deadly in pink: the impact of cigarette packaging among young women. Tob Control. 2011;20(5):353-360.

12. Gendall P, Hoek J, Thomson G, et al. Young adults' interpretations of tobacco brands: implications for tobacco control. Nicotine Tob Res. 2011;13(10):911-918.

13. Hammond D, Dockrell M, Arnott D, Lee A, McNeill A. Cigarette pack design and perceptions of risk among UK adults and youth. Eur J Public Health. 2009;19(6):631-637.

14. Hammond D, Doxey J, Daniel S, Bansal-Travers M. Impact of femaleoriented cigarette packaging in the United States. Nicotine Tob Res. 2011;13(7):579-588.

15. Kotnowski K, Hammond D. The impact of cigarette pack shape, size and opening: evidence from tobacco company documents. Addiction. 2013;108(9):1658-1668.

16. Mutti S, Hammond D, Borland R, Cummings MK, O’Connor RJ, Fong GT. Beyond light and mild: cigarette brand descriptors and perceptions of risk in the International Tobacco Control (ITC) Four Country Survey. Addiction. 2011;106(6):1166-1175.
17. Wilson N, Weerasekera D, Peace J, Edwards R, Thomson G, Devlin M. Misperceptions of "light" cigarettes abound: national survey data. $B M C$ Public Health. 2009;9:126.

18. Yong HH, Borland R, Cummings KM, et al. Impact of the removal of misleading terms on cigarette pack on smokers' beliefs about 'light/ mild' cigarettes: cross-country comparisons. Addiction. 2011;106(12): 2204-2213.

19. Freeman B, Chapman S, Rimmer M. The case for the plain packaging of tobacco products. Addiction. 2008;103(4):580-590.

20. Hammond D. "Plain packaging" regulations for tobacco products: the impact of standardizing the color and design of cigarette packs. Salud Publica Mex. 2010;52 Suppl 2:S226-S232.

21. Mitchell AD, Studdert DM. Plain packaging of tobacco products in Australia: a novel regulation faces legal challenge. JAMA. 2012;307(3): 261-262.

22. World Health Organization [homepage on the Internet]. WHO Framework Convention on Tobacco Control. Geneva, Switzerland; 2003. Available from: http://www.who.int/tobacco/framework/ download/en/. Accessed January 28, 2015.

23. World Health Organization [homepage on the Internet]. WHO Framework Convention on Tobacco Control (FCTC). United Kingdom of Great Britain and Northern Ireland: regulations for standardized packaging in the pipeline; 2015. Available from: http://www.who.int/fctc/ en/. Accessed January 28, 2015.

24. Sanders-Jackson AN, Song AV, Hiilamo H, Glantz SA. Effect of the Framework Convention on Tobacco Control and voluntary industry health warning labels on passage of mandated cigarette warning labels from 1965 to 2012: transition probability and event history analyses. Am J Public Health. 2013;103(11):2041-2047.

25. Centers for Disease Control and Prevention (CDC). Cigarette package health warnings and interest in quitting smoking - 14 countries, 2008-2010. MMWR Morb Mortal Wkly Rep. 2011;60(20):645-651.

26. Emery LF, Romer D, Sheerin KM, Jamieson KH, Peters E. Affective and cognitive mediators of the impact of cigarette warning labels. Nicotine Tob Res. 2014;16(3):263-269.

27. Hammond D, Fong GT, McNeill A, Borland R, Cummings KM. Effectiveness of cigarette warning labels in informing smokers about the risks of smoking: findings from the International Tobacco Control (ITC) Four Country Survey. Tob Control. 2006;15 Suppl 3:iii19-iii25.

28. Hammond D, Fong GT, Borland R, Cummings KM, McNeill A, Driezen P. Text and graphic warnings on cigarette packages: findings from the international tobacco control four country study. Am J Prev Med. 2007;32(3):202-209.

29. Nonnemaker JM, Choiniere CJ, Farrelly MC, Kamyab K, Davis KC. Reactions to graphic health warnings in the United States. Health Educ Res. 2015;30(1):46-56.

30. Swayampakala K, Thrasher JF, Hammond D, et al. Pictorial health warning label content and smokers' understanding of smoking-related risks-a cross-country comparison. Health Educ Res. 2015;30(1): $35-45$.

31. Thrasher JF, Osman A, Moodie C, et al. Promoting cessation resources through cigarette package warning labels: a longitudinal survey with adult smokers in Canada, Australia and Mexico. Tob Control. 2015;24(e1):e23-e31.

32. Villanti AC, Cantrell J, Pearson JL, Vallone DM, Rath JM. Perceptions and perceived impact of graphic cigarette health warning labels on smoking behavior among US Young adults. Nicotine Tob Res. 2014;16(4):469-477.

33. Yong HH, Borland R, Thrasher JF, et al. Mediational pathways of the impact of cigarette warning labels on quit attempts. Health Psychol. 2014;33(11):1410-1420.

34. Chapman S, Freeman B. Removing the Emperor's Clothes: Australia and Tobacco Plain Packaging. Australia: Sydney University Press; 2014.

35. Cunningham R, Kyle K. The case for plain packaging. Tob Control. 1995;4(1):80-86. 
36. Warner KE. An endgame for tobacco? Tob Control. 2013;22 Suppl 1: i3-i5.

37. King's College London. Chantler C. Standardised Packaging of Tobacco. Report of the independent review undertaken by Sir Cyril Chantler; 2014. Available from http://www.kcl.ac.uk/health/10035-TSO2901853-Chantler-Review-ACCESSIBLE.PDF. Accessed February 19, 2015.

38. Commonwealth of Australia [homepage on the Internet]. Tobacco Plain Packaging Act 2011 - C2013A00148. Available from: http://www comlaw.gov.au/Details/C2013C00190. Accessed January 28, 2015.

39. High Court of Australia [homepage on the Internet]. Commonwealth of Australia. Case S389/2411. British American Tobacco Australasia Limited and Ors v. The Commonwealth of Australia; 2011. Available from: http://www.hcourt.gov.au/cases/case-s389/2011. Accessed January 28, 2015.

40. Pechey R, Spiegelhalter D, Marteau TM. Impact of plain packaging of tobacco products on smoking in adults and children: an elicitation of international experts' estimates. BMC Public Health. 2013;13:18.

41. West R. Preventing tobacco companies from advertising using their packaging could be an important component of comprehensive tobacco control: a commentary on Australia's plain packaging of cigarettes. Drug Alcohol Rev. 2011;30(6):681-682.

42. Sweanor DT. Effective beats dramatic: a commentary on Australia's plain packaging of cigarettes. Drug Alcohol Rev. 2011;30(6):683-684.

43. Crosbie E, Glantz SA. Tobacco industry argues domestic trademark laws and international treaties preclude cigarette health warning labels, despite consistent legal advice that the argument is invalid. Tob Control. 2014;23(3):e7.

44. O'Dowd A. UK government may face legal challenge from Philip Morris over plain cigarette packaging. BMJ. 2014;349:g5172.

45. Bayer R, Gostin L, Marcus-Toll D. Repackaging cigarettes-will the courts thwart the FDA? N Engl J Med. 2012;367(22):2065-2067.

46. Outterson K. Smoking and the First Amendment. $N$ Engl J Med. 2011;365(25):2351-2353.

47. Stead M, Moodie C, Angus K, et al. Is consumer response to plain/ standardised tobacco packaging consistent with framework convention on tobacco control guidelines? A systematic review of quantitative studies. PLoS One. 2013;8(10):e75919.

48. Fong GT, Cummings KM, Borland R, et al. The conceptual framework of the International Tobacco Control (ITC) Policy Evaluation Project. Tob Control. 2006;15 Suppl 3:iii3-iii11.

49. McCool J, Webb L, Cameron LD, Hoek J. Graphic warning labels on plain cigarette packs: will they make a difference to adolescents? Soc Sci Med. 2012;74(8):1269-1273.

50. Scheffels J, Saebo G. Perceptions of plain and branded cigarette packaging among Norwegian youth and adults: a focus group study. Nicotine Tob Res. 2013;15(2):450-456.

51. Van Hal G, Van Roosbroeck S, Vriesacker B, Arts M, Hoeck S, Fraeyman J. Flemish adolescents' perceptions of cigarette plain packaging: a qualitative study with focus group discussions. BMJ Open. 2012; 2(6).

52. Ford A, Mackintosh AM, Moodie C, Richardson S, Hastings G. Cigarette pack design and adolescent smoking susceptibility: a crosssectional survey. BMJ Open. 2013;3(9):e003282.

53. Moodie C, Ford A, Mackintosh AM, Hastings G. Young people's perceptions of cigarette packaging and plain packaging: an online survey. Nicotine Tob Res. 2012;14(1):98-105.

54. Germain D, Wakefield MA, Durkin SJ. Adolescents' perceptions of cigarette brand image: does plain packaging make a difference? J Adolesc Health. 2010;46(4):385-392.

55. Hammond D, Daniel S, White CM. The effect of cigarette branding and plain packaging on female youth in the United Kingdom. JAdolesc Health. 2013;52(2):151-157.

56. Hammond D, White C, Anderson W, Arnott D, Dockrell M. The perceptions of UK youth of branded and standardized, 'plain' cigarette packaging. Eur J Public Health. 2014;24(4):537-543.
57. Lund I, Scheffels J. Young smokers and non-smokers perceptions of typical users of plain vs branded cigarette packs: a between-subjects experimental survey. BMC Public Health. 2013;13:1005.

58. Scheffels J, Lund I. The impact of cigarette branding and plain packaging on perceptions of product appeal and risk among young adults in Norway: A between-subjects experimental survey. BMJ Open. 2013;3(12):e003732.

59. Maynard OM, Munafò MR, Leonards U. Visual attention to health warnings on plain tobacco packaging in adolescent smokers and nonsmokers. Addiction. 2013;108(2):413-419.

60. Jha P, Peto R. Global effects of smoking, of quitting, and of taxing tobacco. N Engl J Med. 2014;370(1):60-68.

61. Arora M, Tewari A, Grills N, et al. Exploring Perception of Indians about Plain Packaging of Tobacco Products: A Mixed Method Research. Front Public Health. 2013;1:35.

62. Hoek J, Gendall P, Gifford H, et al. Tobacco branding, plain packaging, pictorial warnings, and symbolic consumption. Qual Health Res. 2012;22(5):630-639.

63. Borland R, Savvas S. The effects of variant descriptors on the potential effectiveness of plain packaging. Tob Control. 2014;23(1):58-63.

64. Gallopel-Morvan K, Moodie C, Hammond D, Eker F, Beguinot E, Martinet Y. Consumer perceptions of cigarette pack design in France: a comparison of regular, limited edition and plain packaging. Tob Control. 2012;21(5):502-506.

65. Hoek J, Gendall P, Maubach N, Edwards R. Strong public support for plain packaging of tobacco products. Aust $N Z J$ Public Health. 2012;36(5):405-407.

66. Gallopel-Morvan K, Moodie C, Eker F, Beguinot E, Martinet Y. Perceptions of plain packaging among young adult roll-your-own smokers in France: a naturalistic approach. Tob Control. 2015;24(e1):e39-e44.

67. Moodie C, Mackintosh AM, Hastings G, Ford A. Young adult smokers' perceptions of plain packaging: a pilot naturalistic study. Tob Control. 2011;20(5):367-373.

68. Moodie CS, Mackintosh AM. Young adult women smokers' response to using plain cigarette packaging: a naturalistic approach. BMJ Open. 2013;3(3)

69. Guillaumier A, Bonevski B, Paul C, Durkin S, D’Este C. Socioeconomically disadvantaged smokers' ratings of plain and branded cigarette packaging: an experimental study. BMJ Open. 2014;4(2): e004078.

70. Wakefield M, Germain D, Durkin S, Hammond D, Goldberg M, Borland R. Do larger pictorial health warnings diminish the need for plain packaging of cigarettes? Addiction. 2012;107(6):1159-1167.

71. Wakefield MA, Germain D, Durkin SJ. How does increasingly plainer cigarette packaging influence adult smokers' perceptions about brand image? An experimental study. Tob Control. 2008;17(6):416-421.

72. Al-Hamdani M. The effect of cigarette plain packaging on individuals' health warning recall. Healthc Policy. 2013;8(3):68-77.

73. Mays D, Niaura RS, Evans WD, Hammond D, Luta G, Tercyak KP. Cigarette packaging and health warnings: the impact of plain packaging and message framing on young smokers. Tob Control. 2015;24(e1): e87-e92.

74. Thrasher JF, Rousu MC, Hammond D, Navarro A, Corrigan JR. Estimating the impact of pictorial health warnings and "plain" cigarette packaging: evidence from experimental auctions among adult smokers in the United States. Health Policy. 2011;102(1):41-48.

75. Hogarth L, Maynard OM, Munafò MR. Plain cigarette packs do not exert Pavlovian to instrumental transfer of control over tobacco-seeking. Addiction. 2015;110(1):174-182.

76. Maynard OM, Attwood A, O'Brien L, et al. Avoidance of cigarette pack health warnings among regular cigarette smokers. Drug Alcohol Depend. 2014;136:170-174.

77. Munafò MR, Roberts N, Bauld L, Leonards U. Plain packaging increases visual attention to health warnings on cigarette packs in non-smokers and weekly smokers but not daily smokers. Addiction. 2011;106(8):1505-1510. 
78. White CM, Hammond D, Thrasher JF, Fong GT. The potential impact of plain packaging of cigarette products among Brazilian young women: an experimental study. BMC Public Health. 2012;12:737.

79. Wakefield MA, Hayes L, Durkin S, Borland R. Introduction effects of the Australian plain packaging policy on adult smokers: a cross-sectional study. BMJ Open. 2013;3(7).

80. Dunlop SM, Dobbins T, Young JM, Perez D, Currow DC. Impact of Australia's introduction of tobacco plain packs on adult smokers' packrelated perceptions and responses: results from a continuous tracking survey. BMJ Open. 2014;4(12):e005836.

81. Young JM, Currow D, Dunlop S. The association between tobacco plain packaging and Quitline calls. Med J Aust. 2014;200(6):314-315.

82. Swift E, Borland R, Cummings KM, et al. Australian smokers'support for plain or standardised packs before and after implementation: findings from the ITC Four Country Survey. Tob Control. Epub November 10 2014.

83. Zacher M, Bayly M, Brennan E, et al. Personal tobacco pack display before and after the introduction of plain packaging with larger pictorial health warnings in Australia: an observational study of outdoor cafe strips. Addiction. 2014;109(4):653-662.

84. Australian Government Department of Health [homepage on the Internet]. Tobacco key facts and figures [updated February 13, 2015]. Available from: http://www.health.gov.au/internet/main/publishing. nsf/Content/tobacco-kff. Accessed February 19, 2015.

85. Carter OB, Mills BW, Phan T, Bremner JR. Measuring the effect of cigarette plain packaging on transaction times and selection errors in a simulation experiment. Tob Control. 2012;21(6):572-577.

86. Carter O, Welch M, Mills B, Phan T, Chang P. Plain packaging for cigarettes improves retail transaction times. BMJ. 2013;346:f1063.

87. Bayly M, Scollo M, Wakefield M. No lasting effects of plain packaging on cigarette pack retrieval time in small Australian retail outlets. Tob Control. 2015;24(e1):e108-e109.

88. Wakefield M, Bayly M, Scollo M. Product retrieval time in small tobacco retail outlets before and after the Australian plain packaging policy: real-world study. Tob Control. 2014;23(1):70-76.

89. Moodie C, Hastings G, Joossens L. Young adult smokers' perceptions of illicit tobacco and the possible impact of plain packaging on purchase behaviour. Eur J Public Health. 2012;22(2):251-253.
90. Scollo M, Zacher M, Durkin S, Wakefield M. Early evidence about the predicted unintended consequences of standardised packaging of tobacco products in Australia: a cross-sectional study of the place of purchase, regular brands and use of illicit tobacco. BMJ Open. 2014;4(8):e005873.

91. Scollo M, Bayly M, Wakefield M. Availability of illicit tobacco in small retail outlets before and after the implementation of Australian plain packaging legislation. Tob Control. 2015;24(e1):e45-e51.

92. Evans-Reeves KA, Hatchard JL, Gilmore AB. 'It will harm business and increase illicit trade': an evaluation of the relevance, quality and transparency of evidence submitted by transnational tobacco companies to the UK consultation on standardised packaging 2012. Tob Control. Epub December 3, 2014.

93. McGrady B. Implications of ongoing trade and investment disputes concerning tobacco: Philip Morris v. Uruguay (August 1, 2011). In: Voon T, Mitchell AD, Liberman J, Ayres G, editors. Public Health and Plain Packaging of Cigarettes: Legal Issues. Edward Elgar; 2012.

94. The Guardian [homepage on the Internet]. Doward J. US free market group tries to halt sales of cigarettes in plain packets in UK. The Guardian (London); 2012. Available from: http://www.theguardian. com/society/2012/jul/15/cigarettes-plain-packets-alec-koch-brothers. Accessed January 28, 2015.

95. AFTINET. Australian High Court rules against big tobacco on plain packaging [press release]. AFTINET Australian Fair Trade and Investment Network Ltd; 2014. Available from: http://aftinet.org.au/cms/ node/519. Accessed January 28, 2015.

96. Voon TS, Mitchell AD. Implications of WTO law for plain packaging of tobacco products. In: Mitchell A, Voon T, Liberman J, editors. Public Health and Plain Packaging of Cigarettes: Legal Issues. Edward Elgar UK; 2012.

97. World Trade Organization [homepage on the Internet]. United States - Measures Affecting the Production and Sale of Clove Cigarettes: Current Status. WTO Dispute Settlement: DS406; 2014. Available from: http://www.wto.org/english/tratop_e/dispu_e/cases_e/ ds406_e.htm. Accessed January 28, 2015.

98. Kraemer JD, Baig SA. Analysis of legal and scientific issues in court challenges to graphic tobacco warnings. Am J Prev Med. 2013;45(3): 334-342.
Risk Management and Healthcare Policy

\section{Publish your work in this journal}

Risk Management and Healthcare Policy is an international, peerreviewed, open access journal focusing on all aspects of public health, policy, and preventative measures to promote good health and improve morbidity and mortality in the population. The journal welcomes submitted papers covering original research, basic science, clinical \& epidemio-
Dovepress

logical studies, reviews and evaluations, guidelines, expert opinion and commentary, case reports and extended reports. The manuscript management system is completely online and includes a very quick and fair peerreview system, which is all easy to use. Visit http://www.dovepress.com/ testimonials.php to read real quotes from published authors. 